\title{
Placenta accreta and emergency cesarean delivery correlates to cervical length and transcervical placental thickness measurement
}

\author{
Nahla W. Shady ${ }^{1}$, Hany F. Sallam ${ }^{1}$, Ahmed M. Abbas ${ }^{2 *}$
}

\begin{abstract}
${ }^{1}$ Department of Obstetrics and Gynaecology, Faculty of Medicine. Aswan University, Aswan, Egypt
${ }^{2}$ Department of Obstetrics and Gynaecology, Faculty of Medicine. Assiut University, Assiut, Egypt
\end{abstract}

Received: 31 August 2017

Accepted: 25 September 2017

\section{*Correspondence:}

Dr. Ahmed M. Abbas,

E-mail: bmr90@hotmail.com

Copyright: ( ) the author(s), publisher and licensee Medip Academy. This is an open-access article distributed under the terms of the Creative Commons Attribution Non-Commercial License, which permits unrestricted non-commercial use, distribution, and reproduction in any medium, provided the original work is properly cited.

\begin{abstract}
Background: The study aims to evaluate the effect of cervical length and the transcervical placental thickness measurement at 28-30 weeks gestation in predicting the risk of antepartum haemorrhage (APH) and emergency preterm caesarean delivery (CD) in women with placenta previa accreta.

Methods: A prospective cohort study conducted at Aswan university hospital from June 2015 to April 2017 included one hundred and five cases diagnosed as placenta previa accreta by transvaginal ultrasound (TVS) between 28-30 weeks gestation were divided into three groups according to their cervical length which measured by TVS: group I (cervical length $>30 \mathrm{~mm}$ ), group II (cervical length $20-30 \mathrm{~mm}$ ) and group III (cervical length $<20 \mathrm{~mm}$ ). Also, placental thickness measurement was done. Cervical length and placental thickness and correlated with the clinical outcome regarding to gestational age at delivery, APH, emergency $\mathrm{CD}$ due to massive haemorrhage, the need for blood transfusion and caesarean hysterectomy.

Results: APH and emergency CD due to massive bleeding were significantly higher in cases with short cervical length and thick placenta. APH occurred in 6 cases (15\%) in group I, 14 cases (40\%) in group II and 24 cases $(80 \%)$ in group III, $(\mathrm{p}=0.0001)$. Emergency CD in group I was performed in 5 cases $(12.5 \%), 12$ cases $(34.3 \%)$ in group II and 24 cases $(80 \%)$ in group III, $(\mathrm{p}=0.0001)$. The incidence of APH was higher in thick placenta [6 cases $(42.9 \%)$ compared to none with thin placenta in group I ( $\mathrm{p}=0.001), 13$ cases $(68.4 \%)$ compared to one case $(6.2 \%)$ in group II $(\mathrm{p}=0.0001)$ and 21 cases $(100 \%)$ compared to 3 cases $(33.3 \%)$ in group III $(\mathrm{p}=0.0001)]$.

Conclusions: Short cervical length and increased placental thickness may predict the risk of APH and emergency preterm $\mathrm{CD}$ in patients with placenta accreta.
\end{abstract}

Keywords: Cervical length, Cesarean delivery, Placental thickness, Placenta accreta

\section{INTRODUCTION}

Abnormally invasive placentas are a life-threatening condition characterized by placental villi being abnormally adherent to the myometrium as a result of the absence of, or defects in, the normal decidua basalis and the fibrinous Nita Buch's layer. ${ }^{1}$ They are commonly classified into three distinct grades according to the degree of the placental villi invasion into the myometrium: placenta accreta (placental villi are attached to the decidua surface of the myometrium), placenta increta (placental villi more deeply invading into the myometrium) and placenta percreta (placental villi invade through the myometrium and the uterine serosa and sometimes into adjacent organs, such as the bladder). ${ }^{2}$

In a clinical setting, these histopathological differences are probably non-existent. Therefore, the term "placenta accreta" is used as a general term to describe all of these three conditions. ${ }^{2}$ 
Placenta accreta (PA) become the most serious problem during third stage of delivery and some obstetricians call it "Obstetricians Nightmare". 3 PA leads to massive intractable haemorrhage with loss of about 3-5 litres of blood, disseminated intravascular coagulopathy, adult respiratory distress syndrome, massive blood transfusion, electrolyte imbalance, and renal failure. ${ }^{4}$

The incidence of PA has increased remarkably, in direct relationship to the increasing caesarean delivery (CD) rate. The incidence of PA was estimated in the 1980s to be 1 in 2500 deliveries; in 2012 the American College of Obstetricians and Gynecologists (ACOG) stated the incidence to be as high as 1 in 533 deliveries. Currently, the rate is higher. ${ }^{5,6}$

Scheduled preterm delivery is necessary and justified by many obstetricians to avoid serious adverse maternal consequences of emergency $\mathrm{CD} .^{7}$ It is advised to be in tertiary care hospitals for disciplinary team management and possibility of intensive care unit (ICU) need. ${ }^{8,9}$ The ACOG recommends individualization of the time of delivery. Many studies advocate elective delivery without foetal lung maturity testing after 34 completed weeks. ${ }^{10}$ Recently surveys indicate that most obstetricians do not deliver PA patients until 36 weeks or later. ${ }^{11,12}$

In low resource countries where the neonatal intensive care facilities are inadequate or not available and perinatal mortality due to prematurity is high, we need to individualize the time of delivery according to the risk of antepartum haemorrhage (APH).

Therefore, the aim of this study was to evaluate the role of cervical length and the trans cervical placental thickness measurement at 28-30 weeks gestation in predicting the risk of APH and emergency preterm CD in women with PA.

\section{METHODS}

This study was a prospective cohort study conducted in the Obstetrics and Gynecology Department at Aswan University hospital, between June 2015 and April 2017. The Institutional Ethical Review Board approved the study.

All asymptomatic pregnant women that have been suspected with PA were included in this study, if they fulfill our inclusion criteria: singleton pregnancy, gestational age 28-30 weeks as determined by a reliable date of last normal menstrual period or having first trimester ultrasound (US) defining gestational age.

Diagnosis of PA was confirmed when the lower placental edge completely overlay the internal cervical OS on TVS with one or more of ultrasonographic features suggestive of PA include multiple irregular placental lacunae with a "moth-eaten" or "Swiss cheese" appearance of placenta, thinning of the myometrium overlying the placenta, loss of the retroplacental clear space, invasion of the placenta into the bladder, increased vascularity of the uterine serosa-bladder interface, and turbulent blood flow through the lacunae on Doppler velocimetry.

We excluded women with present or past history of bleeding in the current pregnancy, previous or current history of threatened preterm labor, history of cervical cerclage, ruptured membranes, polyhydramnios, multiple gestation, fetal growth restriction, fetal anomalies and history of medical disorders complicating the pregnancy.

Informed consent was taken from all participants, full history including parity, gestational age and numbers of previous CD. Ultrasound examinations were performed using (GE healthcare, Voluson 58) with a multifrequency 5-7.5 $\mathrm{MHz}$ transvaginal probe between 28-30 weeks. Cervical evaluation was performed according to a standardized technique: women were asked to void their bladder before the examination. A true sagittal plane was obtained in order to visualize the full length of the cervical canal and cervical length was measured three times by placing the calipers on the internal and external OS. The shortest measurement was then recorded.

According to the cervical length; women were allocated to three groups. Group I (cervical length $>30 \mathrm{~mm}$ ), Group II (cervical length 20-30 mm) and Group III (cervical length $<20 \mathrm{~mm}$ ). All groups completed follow-up of pregnancy and all cases were planned for elective CD at 37 weeks. If vaginal bleeding occurred prior to the scheduled CD, patients were admitted to the hospital and delivery was decided in accordance with the clinical condition of the patient regardless of gestational age. Induction of fetal lung maturity was carried out by giving $12 \mathrm{mg}$ dexamethasone IM daily for two doses.

The following variables being recorded: gestational age at delivery, occurrence of peripartum bleeding, emergency $\mathrm{CD}$ due to massive hemorrhage, the need for blood transfusion and the need for cesarean hysterectomy. Also, placental thickness was measured in all groups. The placental thickness was measured over the internal cervical OS. Thin placenta was considered when the thickness $\leq 1 \mathrm{~cm}$ and thick placenta $>1 \mathrm{~cm}$. The results of cervical length and placental thickness measurements were not disclosed to the obstetricians who perform the cesarean delivery.

Data were entered and statistically analyzed using the Statistical Package for Social Sciences (SPSS) version 22. Qualitative data were described as numbers and percentages. $\chi^{2}$ test was used for comparison between groups. Quantitative data were described as means (SD) or medians, as appropriate. They were tested for normality by Kolmogorov-Smirnov test. In the normally distributed variables, one-way ANOVA test was used for comparison between groups. In the non-normally distributed variables, Kruskal-Wallis test and Mann Whitney test were used for comparison between groups, 
as appropriate. Odds ratios and their $95 \%$ confidence interval were calculated. $\mathrm{p}$ value $\leq 0.05$ was considered to be statistically significant.

\section{RESULTS}

The study started by one hundred twenty cases diagnosed as PA by TVS fulfilling the inclusion criteria. Fifteen cases were discontinued the study. The final study group was one hundred and five cases divided to three groups according to their cervical length measured by TVS.

Table 1 showed patient characteristics and pregnancy outcome. There was no statistically significant difference in related to age or parity. A statistically significant difference was present in relation to previous numbers of $\mathrm{CD}$ between (group I and III) and (group II and III) $(\mathrm{p}=$ $0.023,0.049$ respectively).

Table 1: Patients' characteristics and pregnancy outcomes in the study groups.

\begin{tabular}{|c|c|c|c|c|}
\hline Variables & $\begin{array}{l}\text { I: cervical length } \\
>30 \mathrm{~mm}(\mathrm{n}=40)\end{array}$ & $\begin{array}{l}\text { II: cervical length } \\
20-30 \mathrm{~mm}(\mathrm{n}=35)\end{array}$ & $\begin{array}{l}\text { III: cervical length } \\
<20 \mathrm{~mm}(\mathrm{n}=30)\end{array}$ & p-value \\
\hline Age (years) & $30.48 \pm 3.99$ & $30.48 \pm 4.39$ & $31.20 \pm 4.82$ & 0.191 \\
\hline Parity & $3(1.5)$ & $3(1-5)$ & $3(1-5)$ & 0.082 \\
\hline Previous CD & $3(1.5)$ & $3(1-4)$ & $3(1-5)$ & $\begin{array}{l}0.045 * \\
(0.47 / 0.023 * / 0.049 *)\end{array}$ \\
\hline $\begin{array}{l}\text { Gestational age at } \\
\text { delivery (weeks) }\end{array}$ & $36.6 \pm 0.84$ & $34.66 \pm 5.72$ & $33.37 \pm 2.17$ & $\begin{array}{l}0.001 * \\
(0.02 * / 0.0001 * / 0.146)\end{array}$ \\
\hline $\begin{array}{l}\text { Placental thickness } \\
(\mathrm{cm})\end{array}$ & $1.00(0.5-1.8)$ & $1.3(0.5-1.8)$ & $1.45(0.5-1.9)$ & $\begin{array}{l}0.021 * \\
(0.106 / 0.004 * / 0.405)\end{array}$ \\
\hline
\end{tabular}

CD: caesarean delivery; *statistical significant difference p-values (groups I versus II / I versus III / II versus III); Variables are presented as mean \pm standard deviation or median (minimum-maximum)

The mean gestational age at CD was significantly lower in group II and III (34.66 \pm 5.72$), \quad(33.37 \pm 2.17)$ respectively versus group I $(36.6 \pm 0.84)$ with statistically significant difference between group I and II $(p=0.02)$ and group I and III ( $\mathrm{p}=0.0001)$.

The placental thickness median in group I was (1.00), group II (1.3) and group III (1.45) with statistically significant difference between group I and group III $(\mathrm{p}=0.004)$.
Table 2 showed the clinical outcome in relation to the cervical length. APH was observed in 6 cases $(15 \%)$ in group I, 14 cases (40\%) in group II and 24 cases (80\%) in group III. These figures showed very high statistically significant difference $(\mathrm{p}=0.0001)$. The need for emergent CD in group I was 5 cases $(12.5 \%), 12$ cases $(34.3 \%)$ in group II and 24 cases $(80 \%)$ in group III with a statistically significant difference between the three groups $(\mathrm{p}=0.0001)$.

Table 2: The clinical outcomes in the study groups in relation to the cervical length.

\begin{tabular}{|c|c|c|c|c|}
\hline Outcomes & $\begin{array}{l}\text { I: cervical length } \\
>30 \mathrm{~mm}(\mathrm{n}=\mathbf{4 0})\end{array}$ & $\begin{array}{l}\text { II: cervical length } \\
\text { 20-30 } \mathrm{mm}(\mathrm{n}=35)\end{array}$ & $\begin{array}{l}\text { III: cervical length } \\
<20 \mathrm{~mm}(\mathrm{n}=30)\end{array}$ & p-value \\
\hline $\mathrm{APH}$ & $6(15)$ & $14(40)$ & $24(80)$ & $\begin{array}{l}0.0001 * \\
(0.015 * / 0.0001 * / 0.001 *)\end{array}$ \\
\hline Emergent CD & $5(12.5)$ & $12(34.3)$ & $24(80)$ & $\begin{array}{l}0.0001 * \\
(0.025 * / 0.0001 * / 0.0001 *)\end{array}$ \\
\hline $\begin{array}{l}\text { Peripartum blood } \\
\text { transfusion }\end{array}$ & $15(37.5)$ & $20(57.1)$ & $26(86.7)$ & $\begin{array}{l}0.0001 * \\
(0.089 / 0.0001 * / 0.009 *)\end{array}$ \\
\hline $\begin{array}{l}\text { Caesarean } \\
\text { hysterectomy }\end{array}$ & $5(12.5)$ & 8 (22.9) & $14(46.7)$ & $\begin{array}{l}0.005 * \\
(0.237 / 0.001 * / 0.043 *)\end{array}$ \\
\hline
\end{tabular}

APH: antepartum haemorrhage; CD: caesarean delivery; *statistical significant difference p-values (groups I versus II / I versus III / II versus III); All variables are presented as number (\%) and Chi-Square test was used to calculate the difference

The need for peripartum blood transfusion was 15 cases $(37.5 \%)$ in group I, 20 cases $(57.1 \%)$ in group II and 26 cases $(86.7 \%)$ in group III with statistically significant difference between group I and group III $(\mathrm{p}=0.0001)$, between group II and group III $(\mathrm{p}=0.009)$. 
Table 3 showed the clinical outcome in relation to the placental thickness. The incidence of APH was higher in thick placenta [6 cases $(42.9 \%)$ ] compared to none in cases with thin placenta in group I $(p=0.001)$, 13 cases
(68.4\%) compared to one case $(6.2 \%)$ in group II $(\mathrm{p}=0.0001)$ and 21 cases $(100 \%)$ compared to 3 cases $(33.3 \%)$ in group III $(\mathrm{p}=0.0001)$.

Table 3: The clinical outcomes in the study groups in relation to placental thickness.

\begin{tabular}{|c|c|c|c|c|}
\hline Outcomes & Cervical length & Thin placenta $\leq 1 \mathrm{~cm}$ & Thick placenta $>1 \mathrm{~cm}$ & p-value \\
\hline \multirow{3}{*}{ APH } & $>30 \mathrm{~mm}$ & 0 & $6(42.9)$ & $0.001 *$ \\
\hline & $20-30 \mathrm{~mm}$ & $1(6.2)$ & $13(68.4)$ & $0.0001 *$ \\
\hline & $<20 \mathrm{~mm}$ & $3(33.3)$ & $21(100.0)$ & $0.0001 *$ \\
\hline \multirow{3}{*}{ Emergent CD } & $>30 \mathrm{~mm}$ & 0 & $5(35.7)$ & $0.003 *$ \\
\hline & $20-30 \mathrm{~mm}$ & $1(6.2)$ & $11(57.9)$ & $0.001 *$ \\
\hline & $<20 \mathrm{~mm}$ & $3(33.3)$ & $21(100.0)$ & $0.0001 *$ \\
\hline \multirow{3}{*}{ Peripartum blood transfusion } & $>30 \mathrm{~mm}$ & $5(19.2)$ & $10(71.4)$ & $0.001 *$ \\
\hline & $20-30 \mathrm{~mm}$ & $1(6.2)$ & $19(100.0)$ & $0.0001 *$ \\
\hline & $<20 \mathrm{~mm}$ & $5(55.6)$ & $21(100.0)$ & $0.005^{*}$ \\
\hline \multirow{3}{*}{ Caesarean hysterectomy } & $>30 \mathrm{~mm}$ & 0 & $5(35.7)$ & $0.003^{*}$ \\
\hline & $20-30 \mathrm{~mm}$ & 0 & $8(42.1)$ & $0.004 *$ \\
\hline & $<20 \mathrm{~mm}$ & 0 & $14(66.7)$ & $0.001 *$ \\
\hline
\end{tabular}

APH: antepartum hemorrhage; CD: cesarean delivery; *statistical significant difference; All variables are presented as number (\%) and Chi-Square test was used to calculate the difference

Additionally, the incidence of emergency $\mathrm{CD}$ was higher in thick placenta [5 cases $(35.7 \%)$ ] compared to none with thin placenta in group I $(\mathrm{p}=0.003), 11$ cases $(57.9 \%)$ compared to 1 case $(6.2 \%)$ in group II (p = $0.0001), 21$ cases $(100 \%)$ compared to 3 cases $(33.3 \%)$ in group III $(\mathrm{p}=0.0001)$.

\section{DISCUSSION}

The current study revealed that lower cervical length and increase in the tans cervical placental thickness may increase the risk of APH, emergency $\mathrm{CD}$, need for blood transfusion and cesarean hysterectomy.

Data are limited regarding the timing of delivery in women with PA. The recent recommendation for planned late-preterm delivery was based on a decision analysis, which concluded that delivery at 34 weeks of gestation was associated with the highest quality-adjusted lifeyears under the base case assumptions. ${ }^{13,14}$ However, weekly estimates of the risk of hemorrhage necessitating delivery were derived from cases of placenta previa and accreta from 30 to 40 years ago, when prenatal detection of invasion and even previa was far less sophisticated. ${ }^{15,16}$

Wright and colleagues recently reported that pregnancies with PA delivered earlier in gestation "before 34 weeks of gestation" had higher estimated blood loss and required more blood transfusions than those delivered after 37 weeks of gestation. ${ }^{17}$ Timing of delivery depends upon clinical circumstances; however, most authorities favor delivery at $340 / 7$ to $356 / 7$ weeks with or without antenatal corticosteroid administration. ${ }^{18}$ Ideally, the delivery should be scheduled at a time with optimal personnel availability at a facility prepared to manage significant obstetric hemorrhage.

A recent survey by Wright et al found that, when PA was suspected, delivery was scheduled either at 36 weeks of gestation (in $39 \%$ of cases) or at 38 weeks of gestation (in $34 \%$ of cases). The authors conclude that data were needed to guide the timing of delivery for women with placenta accreta. ${ }^{12}$

Neonatal risks should be considered when planning delivery of women with suspected PA. Fetuses born in the late preterm period have significantly higher mortality and morbidity rates when compared with neonates born at term. ${ }^{19}$ Even with mature amniotic fluid testing, morbidity remains significantly higher in preterm neonates. ${ }^{20}$ These risks must be balanced against potential risks of maternal hemorrhagic complications if delivery is delayed..$^{7,21}$

The increased risk of preterm hemorrhage in women with complete placenta previa and short cervix could be explained by the fact that with a short cervix the chance of spontaneous preterm labor is increased. Sonographic detection of a short cervix has been demonstrated consistently to predict earlier occurrence of labor. ${ }^{22,23} \mathrm{~A}$ shorter cervix among women with placenta previa may therefore also herald premature onset of labor and possible detachment of the placenta from its low insertion.

Classically, hemorrhage from placenta previa during labor has been related to the fact that, due to its inelastic structure, the placenta may not adapt to progressive cervical effacement and undergoes detachment. ${ }^{24}$ 
Predictors for emergent delivery in patient with placenta previa include history of $\mathrm{CD}, \mathrm{APH}$ and the need of antepartum blood transfusion. ${ }^{25}$

Ghi et al were the first to report that in patients with placenta previa, cervical length measurements at the third trimester can be used to predict APH and need for emergency preterm $\mathrm{CD} .{ }^{26}$ In that study, the sensitivity, specificity, and positive and negative predictive values were $83 \%, 77 \%, 48 \%$, and $95 \%$, respectively, for predicting emergency $\mathrm{CD} \leq 34$ weeks' gestation.

Stafford et al found that women with cervical length $\leq 30$ $\mathrm{mm}$ had higher rate of APH requiring delivery (79\% versus $28 \%$; $\mathrm{p}<0.001)$, preterm birth $(69 \%$ versus $21 \%$; $<0.001)$, and cesarean hysterectomy due to PA $(31 \%$ versus $8 \% ; \mathrm{p}=0.016){ }^{27}$ Approximately $80 \%$ of the patients with cervical length $>30 \mathrm{~mm}$ went to term $(<37$ weeks) as compared to only $31 \%$ of those with cervical lengths $\leq 30 \mathrm{~mm}$ ( $\mathrm{p}<0.001)$, the probability of bleeding necessitating delivery ranging from as low as $10-20 \%$ for cervical lengths of $50-60 \mathrm{~mm}$ and as high as $60-100 \%$ for cervical lengths $<10-15 \mathrm{~mm}$.

Sekiguchi et al who followed patients with placenta previa with serial cervical length measurements until 3738 weeks' gestation reported similar findings. ${ }^{28}$ They chose a cervical length cutoff of $\leq 35 \mathrm{~mm}$ to differentiate between those who required preterm $\mathrm{CD}$ versus those who went to term.

However, they also analyze their data according to various cervical length cutoffs; $72 \%$ (33/46) of patients with cervical length $>30 \mathrm{~mm}$ went to term as compared to only $28 \%(13 / 46)$ when the cervix was $<30 \mathrm{~mm}$ (odds ratio $=3.81 ; 95 \% \mathrm{CI}, 1.37-10.62 ; \mathrm{p}=0.018){ }^{28}$

Zaitoun et al reported similar findings regarding the value of cervical length as predictor of bleeding. ${ }^{29}$ They found that patients with placenta previa and cervical length $>30$ $\mathrm{mm}$ had fewer emergency $\mathrm{CD}<36$ weeks $(10 \%$ versus $46 \%, \mathrm{p}=0.002)$ and higher mean birth weights $(2.8$ versus $1.9 \mathrm{~kg}, \mathrm{p}=0.003$ ) as compared to those with cervical lengths $\leq 30 \mathrm{~mm}$.

Similar findings were reported by Fukushima et al where $77 \%$ of patients with placenta previa and cervical length $>30 \mathrm{~mm}$ delivered $>37$ weeks as compared to only $50 \%$ of those with cervical length $\leq 30 \mathrm{~mm}$ who required emergency $\mathrm{CD}$ due to bleeding $<37$ weeks' gestation $(\mathrm{p}=0.04)$; an additional finding was that a short cervix ( $\leq$ $30 \mathrm{~mm}$ ) was associated with morbidly adherent placenta requiring cesarean hysterectomy in $35 \%$ of the cases as compared to only $6 \%$ in those with cervical length $>30$ $\mathrm{mm}(\mathrm{p}=0.004) .^{30}$

In addition to cervical length, placental edge thickness has been evaluated as a predictor of APH and preterm delivery. ${ }^{29,31}$ Studies have shown that patients with placenta previa with "thick" placental edges over the internal OS (>1 cm thickness), as compared to those with thin placental edges over the internal OS $(<1 \mathrm{~cm})$ have a significantly higher frequency of APH episodes (3.8 \pm 1.6 versus 1.6 \pm 0.7$)$, require more emergency $C D<36$ weeks $(53 \%$ versus $26 \% ; \mathrm{p}=0.002)$, require more blood transfusions $(2.4 \pm 2.6$ versus $1.03 \pm 1.3$ units; $\mathrm{p}=0.004)$, and have lower mean birth weight $(1.93 \pm 0.47$ versus $2.72 \pm 0.86 \mathrm{~kg} ; \mathrm{p}=0.006) .{ }^{29,31}$

Present findings regarding a possible association between cervical length and trans cervical placental thickness measurement at 28-30 weeks gestation and the risk of emergent delivery in patients with PA have not been reported previously and may improve our ability to predict the clinical course and to refine obstetric management in these cases. If present data are confirmed on larger numbers, an earlier hospital admission or at least closer clinical monitoring in women with placenta previa and short cervix may become an option with delayed delivery with women with who deemed clinically stable in order to decrease the risks associated with prematurity.

\section{CONCLUSION}

In conclusion, cervical length and trans cervical placental thickness measurements at 28-30 weeks gestation may predict with high accuracy the risk of APH and emergency preterm $\mathrm{CD}$ in patients with PA. We recommend transvaginal measurement of the cervical length and trans cervical placental thickness to be a part of the routine third-trimester scan in women with placenta previa to predict the risk of severe complications and to individualize the patient management.

\section{Funding: No funding sources}

Conflict of interest: None declared

Ethical approval: The study was approved by the Institutional Ethics Committee

\section{REFERENCES}

1. Tseng JJ, Chou MM, Hsiehb YT, Wene MC, Hob ES, Hsuf SL. Differential expression of vascular endothelial growth factor, placenta growth factor and their receptors in placentae from pregnancies complicated by placenta accreta. Placenta. 2006;27:70-8.

2. Oyelese Y, Smulian JC. Placenta previa, placenta accreta, and vasa previa. Obstet Gynecol. 2006;107:927-41.

3. Mohan P, Bajwa S, Sharma S, Kaur P. Placenta percreta-an obstetrician's nightmare. Sri Lanka J Obstet Gynecol. 2010;32(2):39-40.

4. Likis FE, Sathe NA, Morgans AK, Hartmann KE, Young JL, Carlson-Bremer D, et al. Management of Postpartum Hemorrhage. Rockville (MD): Agency for Healthcare Research and Quality (US). 2015:15EHC013-EF. 
5. American College of Obstetricians and Gynecologists Placenta accreta. Committee Opinion No. 529. 2012;120:207-11.

6. Cunningham FG, Leveno KJ, Bloom SL, Spong CY, Dashe JS, et al. William's Obstetrics. 24 ${ }^{\text {th }}$ edition. McGraw-Hill Education; 2014:806.

7. Warshak CR, Ramos GA, Eskander R, Benirschke K, Saenz CC, Kelly TF, et al. Effect of predelivery diagnosis in 99 consecutive cases of placenta accreta. Obstet Gynecol. 2010;115(1):65-9.

8. Eller AG, Bennett MA, Sharshiner M, Masheter C, Soisson AP, Dodson M, et al. Maternal morbidity in cases of placenta accreta managed by a multidisciplinary care team compared with standard obstetric care. Obstet Gynecol 2011;117(2)(1):331-7.

9. Walker MG, Allen L, Windrim RC, Kachura J, Pollard L, Pantazi S, et al. Multidisciplinary management of invasive placenta previa. J Obstet Gynaecol Can. 2013;35(5):417-25.

10. Robinson CJ, Villers MS, Johnson DD, Simpson KN. Timing of elective repeat cesarean delivery at term and neonatal outcomes: a cost analysis. Am J Obstet Gynecol. 2010;202(6):632.e1-632.e6.

11. Esakoff TF, Handler SJ, Granados JM, Caughey AB. PAMUS: Placenta accreta management across the United States. J Matern Fetal Neonatal Med. 2012;25(6):761-5.

12. Wright JD, Silver RM, Bonanno C, Gaddipati S, Lu YS, Simpson LL, et al. Practice patterns and knowledge of obstetricians and gynecologists regarding placenta accreta. J Matern Fetal Neonatal Med. 2013;26(16):1602-9.

13. Silver RM. Abnormal placentation: placenta previa, vasa previa, and placenta accreta. Obstet Gynecol. 2015;126:654-68.

14. Robinson BK, Grobman WA. Effectiveness of timing strategies for delivery of individuals with placenta previa and accreta. Obstet Gynecol. 2010;116:835-42.

15. Silver R, Depp R, Sabbagha RE, Dooley SL, Socol ML, Tamura RK. Placenta previa: aggressive expectant management. Am J Obstet Gynecol. 1984;150:15-22.

16. Brenner WF, Edelman DA, Hendricks $\mathrm{CH}$. Characteristics of patients with placenta previa and results of "expectant management". Am J Obstet Gynecol. 1978;132:180-91.

17. Wright JD, Pri-Paz S, Herzog TJ, Shah M, Bonanno C, Lewin SN, et al. Predictors of massive blood loss in women with placenta accreta. Am J Obstet Gynecol. 2011;205:38.e1-6

18. Watanabe N, Suzuki T, Ogawa K,Kubo T, Sago H. Five-year study assessing the feasibility and safety of autologous blood transfusion in pregnant Japanese women. J Obstet Gynaecol Res. 2011;37(12):1773-7.

19. McIntire DD, Leveno KJ. Neonatal mortality and morbidity rates in late preterm births compared with births at term. Obstet Gynecol. 2008;111:35-41.

20. Bates E, Rouse DJ, Mann ML, Chapman V, Carlo WA, Tita AT. Neonatal outcomes after demonstrated fetal lung maturity before 39 weeks of gestation. Obstet Gynecol. 2010;116:1288-95.

21. Briery CM, Rose CH, Hudson WT, Lutgendorf MA, Magann EF, Chauhan SP, et al. Planned versus emergent cesarean hysterectomy. Am J Obstet Gynecol. 2007;197:154.e1-5.

22. Rozenberg P, Gillet A, Ville Y. Transvaginal sonographic examination of the cervix in asymptomatic pregnant women: review of the literature. Ultrasound Obstet Gynecol. 2002;19:30211.

23. Palacio M, Sanin-Blair J, S'anchez M, Crispi F, G'omezO, Carreras E, et al. The use of a variable cut-off value of cervical length in women admitted for preterm labor before and after 32 weeks. Ultrasound Obstet Gynecol. 2007;29:421-6.

24. Oyelese Y, Smulian JC. Placenta praevia, placenta accreta, and vasa praevia. ObstetGynecol. 2006;107:927-41.

25. Ruiter L, Eschbach SJ, Burgers M, Rengerink KO, vab Pampus MG, Goes BY, et al. Predictors of emergent caesarean delivery in women with placenta previa. Am J Perinatol. 2016;33(14):1407-14.

26. Ghi T, Contro E, Martina T, Piva M, Morandi R, Orsini LF, et al. Cervical length and the risk of antepartum bleeding in women with complet placenta previa. Ultrasound Obestet Gynecol. 2009;33(2):209-12.

27. Stafford IA, Dshe JS, Shiwera SA, Alexander JM, McIntire DD, Leveno KJ. Ultrasound cervical length and the risk of hemorrhage in pregnancies with placenta previa. Obstet Gynecol. 2010;116:595-600.

28. Sekiguchi A, Nakai A, Okuda N, IndeY, Takashita T. Consecutive cervical length measurements as a predictor of preterm cesarean section in complete placenta previa. J Clin Ultrasound. 2015;43:17-22.

29. Zaitoun MM, El Behery MM, El Hameed AAA, Soliman BS. Does cervical length and the lower placental edge thickness measurement correlates with clinical outcome in cases of complete placenta previa? Arch Gynecol Obstet. 2011;284:867-73.

30. Fukushima K, Fujiwara A, Anami A, Fujita Y, Yumoto Y, Sakai A, et al. Cervical length predicts placental adherence and massive hemorrhage in placenta previa. J Obstet Gynaecol Res. 2012;38(1):192-7.

31. Ghourab S. Third-trimester transvaginal ultrasonography in placenta previa: does the shape of the lower placental edge predict clinical outcome. Ultrasound Obstet Gynecol. 2001;18:103-8.

Cite this article as: Shady NW, Sallam HF, Abbas AM. Placenta accreta and emergency cesarean delivery correlates to cervical length and transcervical placental thickness measurement. Int J Reprod Contracept Obstet Gynecol 2017;6:4808-13. 